\title{
Céu: fato ou ficção? Uma abordagem histórico-bíblico-teológica
}

\author{
Heaven: fact or fiction? \\ A historical-biblical-theological approach
}

Tiago Dias de Souza *

\begin{abstract}
Resumo
O texto tem como objetivo descrever o desenvolvimento histórico-bíblicoteológico do conceito de céu desde a antiguidade até a contemporaneidade. O trabalho é resultado de uma pesquisa bibliográfica e documental, com tratamento qualitativo dos dados. As civilizações - desde as mais antigas desenvolveram no decorrer dos tempos uma maneira típica de pensar e falar sobre o céu, tendo como elemento comum o padrão do céu como morada da "Suprema divindade". Independente de lugar ou religião, o céu sempre foi um contraste daquilo que se vive aqui neste mundo. $O$ estudo indicou que a noção de céu não é apenas algo que pertence à religião cristã, ele está relacionado a povos e culturas desde as mais remotas até as atuais. No entanto, no decorrer dos tempos, e em específico neste século presente, o que notamos é uma forte ênfase em espiritualizar o céu, deixando este de ser um lugar.
\end{abstract}

\section{Palavras-chave}

Céu. Vida eterna. Igreja.

\begin{abstract}
The goal of the text is to describe the historical-biblical-theological development of the concept of heaven from antiquity to contemporaneity. The work is the result of a bibliographic and documental research with a qualtitative treatment of the data. The civilizations - from the most ancient ones - developed throughout time a typical way of thinking and talking about heaven having as the common element the pattern of heaven as the dwelling of the "Supreme divinity". Independently of place or religion, heaven has always been a contrast to that which one lives here in this world. The study indicated that the notion of heaven is not something that belongs only to the Christian religion, it is related to peoples and cultures from the most remote times to the current times. However, with the
\end{abstract}

[Texto recebido em setembro de 2016 e aceito em junho de 2017, com base na avaliação cega por pares realizada por pareceristas ad hoc]

* Bacharel em Teologia (Seminário Adventista Latino-Americano de Teologia). Especialista em Liderança Pessoal e Eclesiástica (UNASP/EC). Mestre em Teologia (Faculdades EST). Doutorando em Teologia (Faculdades EST). Bolsista da CAPES. E-mail: pr.tiagodias@hotmail.com 
passing of time, and specifically, in this present century, we notice a strong emphasis on spiritualizing heaven, with this no longer being a place.

\section{Keywords}

Heaven. Eternal life. Church.

\section{Introdução}

Ao analisar a trajetória de povos e culturas ao redor do mundo desde a Antiguidade, passando pelo período Medieval até a Idade Moderna, constatamos que algumas civilizações desde as mais remotas tinham um entendimento místico sobre o céu, comparado ao povo hebreu e à Igreja Cristã Primitiva.

Com o passar do tempo, ocorreram algumas mudanças com relação ao conceito de céu; seja na tradição cristã, como também no mundo oriental.

Em se falando da vida eterna e do céu, o que se percebe aparentemente, é que até mesmo as professas denominações cristãs que deveriam pregar o evangelho eterno que remete o ser humano para uma salvação fora deste mundo - para um lugar onde reine a paz e santidade - não têm desempenhado o seu papel como deveria.

Cabe aqui ressaltar que tanto as igrejas cristãs, de certa forma, têm se omitido quando o assunto é vida eterna ou viver no céu. No decorrer da história, vemos que a igreja tem escrito sobre diversos assuntos. Seus escritos sejam eles quais forem especificamente com relação à escatologia no que diz respeito à vida futura parece que existe um silêncio pairando no tempo. Pelo que nos parece, a igreja tem evitado tocar neste assunto, dando a entender que sua posição escatológica com respeito à vida futura sofreu uma transformação com o decorrer dos tempos.

A grande dúvida é saber se os cristãos não estão brincando de fazer de conta que acreditam em algo que no fundo não têm certeza que seja uma realidade. Quem sabe esta história de céu e vida eterna não seja uma criação do ser humano para poder recorrer a algo supremo quando tudo aqui embaixo vai mal? Ou talvez os cristãos falem do céu só pela força do hábito? Ou quem sabe se isto tudo não foi uma criação da mente de um povo nômade (Hebreus) que por serem forasteiros, sem um lugar fixo para poderem viver, então começaram a sonhar com um lugar utópico?

Enfim, tendo em vista este pano de fundo, surgem algumas perguntas: quais eram as convicções e conceitos de céu dos povos antigos, dos hebreus, da Igreja Primitiva, na Idade Média, do homem moderno, e o que dizer do contemporâneo? O céu é um lugar, um ambiente, ou um estado de espírito?

O relato do Antigo e Novo Testamento, ocorrido há séculos, traz conforto, paz, contentamento, segurança e esperança para pessoas que vivem na sociedade contemporânea, tendo em vista que o conceito de céu é bastante comum tanto na literatura bíblica quanto na considerada secular. 
O texto tem como objetivo descrever o desenvolvimento histórico bíblico-teológico do conceito de céu, desde a antiguidade até a contemporaneidade. O trabalho é resultado de uma pesquisa bibliográfica e documental, com tratamento qualitativo dos dados.

\section{Conceito de céu: uma breve análise de sua construção}

As civilizações - desde as mais antigas - desenvolveram no decorrer dos tempos uma maneira típica de pensar e falar sobre o céu, tendo como elemento comum o padrão do céu como morada da "Suprema divindade", de um ser superior ou como alguns preferem, a morada dos deuses.

O homem sempre contrastou o céu com seu ambiente terrestre (- Terra). Ao relacionamento físico sempre tem correspondido um metafísico. Além de ser um termo especial, "céu" veio a ser uma expressão geral de tudo quanto tem poder sobre o homem, o domínio dos deuses e dos espíritos. ${ }^{1}$

Independente de lugar ou religião, o ser humano tem algo em comum com relação à vida futura, o céu sempre foi um contraste daquilo que se vive aqui neste mundo, foi sempre o anseio de uma sociedade marcada pelo sofrimento presente - seja ele qual for que de certa maneira parece que vai vencer a batalha travada dentro do ser humano em todas as épocas (a busca pela felicidade).

A humanidade sempre sentiu este anseio por viver em um lugar melhor, lugar este onde pudesse gozar a vida em plena felicidade e receber a recompensa final depois de ter peregrinado por um mundo de dor.

A gratificação em uma vida futura onde tudo seja estável é algo que está no íntimo da humanidade; em diversos povos, desde a Antiguidade à sociedade atual, se vê um desejo de receber um galardão por aquilo que se fez de "bom" enquanto estiveram por aqui - na Terra. Este galardão ou recompensa futura tem sido um senso comum nos seres humanos (desde os mais antigos) remetendo-os a buscar no alto a imortalidade.

Por mais que eles não tivessem um conceito formado de céu como temos hoje, algumas culturas tinham algo em comum com o céu bíblico. Alguns tinham o conceito de que o céu era a morada dos deuses, o lugar da habitação dos seres superiores, celestiais. Era visto também com um lugar em que a morte não predominava sobre os que ali viviam.

Nos povos primitivos predomina a ideia de que o homem é filho do céu e da terra, visto que na alquimia o céu figura como o embrião do imortal. [...]. Os mexicanos acreditavam em nove céus, simbolizados arquitetonicamente

1 BROWN, Colin; COENEN, Lothar (Org.). Dicionário internacional de teologia do Novo Testamento. 2. ed. São Paulo: Vida Nova, 2000. p. 338. 
pelos nove estágios das pirâmides. [...]. Entre os astecas aparecem 13 céus, desde os das estrelas até o dos deuses. ${ }^{2}$

Podemos perceber não, apenas por escritos registrados na história, mas igualmente na arquitetura de algumas civilizações que viviam na região onde hoje é o território que compõe a América Latina, que o conceito de céu sempre esteve presente na mentalidade de diversas culturas ao redor do mundo antigo desde seus primórdios. $\mathrm{O}$ homem sempre sentiu a necessidade de alcançar, ou se encontrar com o divino.

\section{Nas religiões antigas}

Conhecer as religiões antigas é importante para compreendermos várias crenças e práticas religiosas que ainda estão presentes em nosso tempo. De acordo como os estudos e escritos de Tácito da Gama Leite Filho, “há semelhanças entre alguns mitos e narrativas bíblicas e entre algumas crenças antigas e modernas. Alguns princípios das religiões antigas ainda são válidos e verdadeiros" ${ }^{3}$ O autor ainda em sua obra sobre o desenvolvimento das religiões declara:

Quanto à vida no além, é a crença mais acentuada do homem primitivo. Criam que, no outro mundo, a pessoa leva uma vida semelhante à que levava na terra. Por isso deviam ser conservados, para lhe assegurar a sobrevivência, túmulos, ornamentos funerários e bens desta vida. Outros criam (e creem) no outro mundo como um lugar melhor que esse. ${ }^{4}$

Em cada religião percebemos a relação entre dois mundos - o sagrado e o profano - o primeiro tendo como referência o céu, e o último, a terra. A busca por uma vida plena distante das mazelas humanas que assolam os habitantes deste planeta tem sido no decorrer das eras o pódio esperado por todos aqueles que passaram pelo mundo dos mortais.

Na Mesopotâmia, por exemplo, alguns estudiosos creem que não existia uma religião definida e única. Acreditavam que existia uma interligação entre o mundo terrestre e o celestial. Para os babilônicos, o rei era um tipo de intercessor, intermediário entre o divino e o humano. "Ele projeta o céu sobre os homens e reflete a terra aos olhos dos deuses". Além do mais se acreditava que "o céu e os ventos estavam sob os pés do deus Marduque". 5

2 SCHLESINGER, Hugo; PORTO, Humberto. Dicionário enciclopédico das religiões. Petrópolis: Vozes/Campus, 1995. p. 564.

3 LEITE FILHO, Tácito da Gama. As religiões antigas. Rio de Janeiro: JUERP, 1994. p. 10.

4 LEITE FILHO, 1994, p. 55.

5 LEITE FILHO, 1994, p. 12-13. 
Os babilônicos acreditavam que o deus Anú era o mais poderoso de todos: “Anú: 'céu'; deus do céu, Rei e pai de todos os deuses". ${ }^{6}$ Os povos da Mesopotâmia tinham a crença de que no céu estava o deus soberano, aquele que regia todos os outros deuses. Havia também a crença de que An era o deus céu, "ele era o pai dos deuses, cujo nome era símbolo do céu e da divindade" ${ }^{7}$

Os babilônicos acreditavam que no céu estava o deus supremo. Em contrapartida os egípcios se preocupavam com a vida após a morte.

Os egípcios eram considerados um dos povos mais religiosos da antiguidade, sua religião se originou dos cultos praticados por povos primitivos que viviam no Delta do Nilo e Rio Eufrates.

Para os egípcios, o céu seria um lugar de prazer onde se desfrutaria dos prazeres da vida em sua totalidade e alcançaria a imortalidade.

Uma crença religiosa ligada a faraó é à ideia do ka. Os textos das pirâmides são dedicados principalmente a procurar a vida eterna para faraó, no reino celestial. Descreve-se sua ascensão ao céu por uma escada (como a de Jacó, em Betel), pela montanha, voando como uma ave. ${ }^{8}$

Os egípcios se preocupavam muito com a vida após a morte. De início, a imortalidade era apenas aos faraós, mas com o passar do tempo se estendeu a outras classes de pessoas.

A crença de que o mundo era achatado e que sustentava o céu era comum para os egípcios. Após a morte, as pessoas viveriam no mundo da eternidade denominado céu. Nada era mais importante para os egípcios do que alcançar a vida eterna. Os egípcios acreditavam que cada pessoa tinha um corpo físico e um ' $\mathrm{ka}$ ' - uma força de vida que continuava após a morte. Este ka precisaria da mesma sustentação que uma pessoa viva.

É óbvio que os egípcios não tinham um conceito sobre o céu tão elaborado quanto o do mundo contemporâneo; mas mesmo assim, acreditam em um céu onde viveriam após a morte. Até mesmo filósofos gregos de grande renome não passaram por alto o assunto do céu.

Já os gregos, pensavam que "no fim da vida, a alma era recompensada ou punida. Os juízes pronunciavam sentença na encruzilhada dos caminhos, um dos quais levava à habitação dos bem-aventurados. Não se tem disponível nenhuma imagem clara das atividades de um lugar como esse". ${ }^{9}$

\footnotetext{
TREIYER, Humberto R. Religiones comparadas. Entre Rios: S.E.M. Colégio Adventista Del Plata, 1966. p. 53. ELIADE, Mircea. Tratado de História das Religiões. São Paulo: Martins Fontes, 1998. p. 232.

LEITE FILHO, 1994, p. 32.

9 DEDEREN, R. (Ed.). Tratado de teologia Adventista do Sétimo Dia. Tatuí: CPB, 2011. p. 1059-1060.
} 
Em sua teogonia, ${ }^{10}$ Hesíodo descreve que o nascimento do Universo se dá da seguinte forma: "No princípio era o caos (vazio primordial) matéria eterna, rudimentar, mas dotada de energia prolífica" ${ }^{11}$ Esta descrição de Hesíodo, em certa medida, relembra o relato da criação no início livro de Gênesis; onde o mundo até então era considero um caos total, "sem forma e vazio".

Notamos que nos clássicos gregos como, por exemplo, em Hesíodo, ele descreve o nascimento do céu como resultado de uma relação afetiva entre os deuses da mitologia que em um determinado momento resultou no nascimento do céu. Além de Hesíodo, Platão e Aristóteles também empregaram a palavra céu em suas obras. Na filosofia, encontram-se declarações de Platão que também traz uma definição de céu.

Em Platão, o "céu" pode ser equacionado com o - tudo, o cosmos (- Terra). Os céus estrelados, considerados como habitação dos deuses, ficaram sendo o ponto de partida para a investigação da existência do conhecimento absoluto. Assim, Platão usou ouranios para denotar o que realmente é e que, verdadeiramente, está vindo a ser. ${ }^{12}$

Observamos que Platão e Hesíodo ambos falam sobre o céu; um discursa sobre o conhecimento absoluto, a habitação dos deuses, o outro em como se dá o surgimento do Universo.

$\mathrm{Na}$ astronomia, Aristóteles apresenta três definições para a terminologia céu. Vejamos:

1. A substância da circunferência externa do mundo, isto é, o corpo natural que está na extrema periferia do universo: nesse sentido, dá o nome de céu à região que se acredita ser a sede da divindade; 2 o corpo que ocupa $o$ lugar mais próximo da circunferência externa do universo e no qual se acham a Lua, o Sol e alguns astros, dos quais de fato dizemos que estão "no céu"; 3. todo corpo que é encerrado pela circunferência externa, isto é, o próprio mundo na sua totalidade. [...]. A doutrina fundamental de Aristóteles acreditava que o "céu" era formado por uma substância diferente da das coisas sublunares, isto é, pelo éter. O éter, que se move somente por movimento circular, não pode sofrer geração nem corrupção. ${ }^{13}$

Ademais de o céu ter uma subdivisão, podemos notar que o céu é bem diferente da terra no sentido de que o celestial não se corrompe; pois, é superior a tudo. Aristóteles tinha uma crença de que este céu era o lugar onde estava situada a sede da divindade.

Quanto aos Hebreus, a Bíblia é a fonte mais importante para se conhecer a respeito de sua história; tendo como seus antepassados os patriarcas - Abraão, Isaac e Jacó - sendo

10 Uma descrição do nascimento dos deuses.

11 LEITE FILHO, 2008, p. 151.

12 COENEN; BROWN, 2000, p. 342.

13 ABBAGNANO, Nicola. Dicionário de filosofia. 5. ed. São Paulo: Martins Fontes, 2007. p. 153. 
Abraão o mais influentes de todos, pois a ele foi feita a promessa, esta que, por sua vez, foi repassada a seus sucessores - como também confirma por Deus - Isaac e Jacó, que posteriormente se tornou Israel.

No pensamento bíblico, o conceito de céu é sempre constante; notamos que o povo hebreu tinha algumas definições sobre o lugar celestial. O conceito de céu do Antigo Testamento tem acertas semelhanças com alguns pensamentos orientais antigos.

As parcas referências sugerem o quadro de um disco achatado que é a terra, cercado pelo oceano, acima do qual o céu ou firmamento forma uma abóboda como uma bacia virada ou uma esfera oca. Acima desta, há o oceano celestial [...]. Segundo o ponto de vista oriental antigo, há muitas esferas celestiais além do firmamento que se pode ver da terra. [...]. O AT, porém, não tem uma cosmogonia única, definitiva e compreensiva [...].14

Existem relatos de muitas tradições acerca da cidade celestial chamada Jerusalém, como também especulações sobre o trono de Deus. Isto não está limitado apenas a religiões de origem bíblica. A relação entre o divino e humano, terrestre e celeste não está descrito apenas nos escritos hebreus, como pudemos ver, os babilônicos e outros povos também tinham seus conceitos sobre o céu.

\section{Nas religiões não bíblicas}

O conceito de céu faz parte também de religiões que se denominam de origem não bíblica, como é o caso das três maiores: budismo, hinduísmo e islamismo. "No budismo existem céus individuais dos budas, segundo a corrente mahayana, mas também o nirvana como um estado de indescritível paz celestial" ${ }^{15}$

Independente da corrente budista eles creem num "paraíso", um lugar de paz, segurança e conforto, onde poderão encontrar a felicidade completa e viver livres de todo tipo males que fazem parte desta vida terrena.

Outra grande religião de origem asiática que mesmo não sendo cristã compartilha do pensamento do céu é o hinduísmo. A religião hindu é hoje a terceira maior religião do mundo, ficando atrás apenas do cristianismo e do islamismo. No hinduísmo, o céu é o princípio ativo masculino oposto à terra que é passiva e feminina. Assim, como o hinduísmo, o islamismo compartilha do pensamento de uma diversidade de céus.

O Islamismo é uma das maiores religiões do mundo, teve sua origem na Arábia por volta do ano 630 A.D pelo seu fundador Maomé. Para o islamismo, “o Corão menciona sete céus como sete estágios de bem-aventurança. Após a morte são recebidas

14 BROWN; COENEN; p. 342.

15 SCHLESSINGER, PORTO, 1995, p. 564. 
imediatamente no céu as almas dos mártires". ${ }^{16}$ Este tem sido o lugar tão almejado pelos mulçumanos em todas as épocas, inclusive na atualidade.

Existem diversas maneiras pela qual as pessoas e grupos sociais, sejam eles quais forem, compreendem o céu. Segundo Schlesinger e Porto, etimologicamente o céu designa abóboda celeste e a morada dos deuses. ${ }^{17}$ No entanto, cada religião possui seu conceito particular de céu, todos têm sua maneira de entender este assunto.

Nas mitologias, o céu é geralmente sinônimo de paz, como terra é mãe. ${ }^{18}$ Percebemos que desde os povos da Antiguidade o céu era tido como um símbolo de serenidade, sossego e bonança.

Contudo, na mitologia chinesa, o céu tem supremacia sobre a terra, isto não quer dizer que seja um dualismo, pelo contrário, eles são separados originalmente. Além do mais, "o céu garante todo desenvolvimento e regula o ciclo da natureza. O ser humano, sobretudo, considerado filho do céu, tem o dever de realizar a vontade do céu como forma ética e suprema" ${ }^{19}$

Mesmo em religiões de origem não cristã como é o caso das religiões citadas anteriormente, encontramos o conceito de céu.

\section{Nas religiões bíblicas}

A palavra céu é muito antiga, pertence ao domínio público, consagrada pelo uso. Segundo Libânio e Bingemer, “o emprego da palavra céu evoca a ideia de 'lugar' ou 'espaço' [...], sua evocação remete ao alto, ao transcendente, àquilo que está acima do homem". 20

Seja qual for o termo empregado, o céu faz parte complementar e fundamental desde sempre, da vida e da esperança dos cristãos. Tanto no Judaísmo, na Igreja Cristã Primitiva, na Católica quanto no protestantismo, o céu representava um lugar; é isto que se nota em declarações apregoadas nos Concílios ecumênicos.

A doutrina do céu é tão bíblica quanto à doutrina do inferno e punição eterna. Mas pouco tem pregado e escrito sobre a vida celestial. De acordo com Tenney "a doutrina bíblica do céu nunca recebeu de um ponto de vista teológico, a consideração que os teólogos têm dado à doutrina do inferno e punição eterna". ${ }^{21}$

\footnotetext{
SCHLESSINGER, PORTO, 1995, p. 564.

SCHLESSINGER, PORTO, 1995, p. 564.

8 SCHLESSINGER, PORTO, 1995, p. 564.

1 KONIG, F.; WALDENFELS, H.; SANDER, L. M. Léxico das religiões. Petrópolis: Vozes, 1998. p. 85.

20 LIBÂNIO, João B; BINGEMER, Maria Clara L. A libertação na história: escatologia cristã. Petrópolis: Vozes, 1985. p. 264-265.

21 TENNEY, Merrill C. (Org.). Enciclopédia da Bíblia. São Paulo: Cultura Cristã, 2008. p. 1020.
} 
Todavia, a palavra céu foi usada no Antigo e Novo Testamento com diversos significados. Não resta dúvida de que os escritores bíblicos empregaram a expressão céu várias vezes, e nem sempre eles estavam se referindo ao mesmo assunto, mas o fato é que a utilizaram centenas de vezes.

Na Bíblia, vemos distintas vezes os escritores usarem a palavra céu descrevendo o céu atmosférico. Tenney argumenta maneira bastante interessante que esses são os três significados básicos da palavra ouranos na literatura grega. De acordo com Tenney, "céu, tanto no AT quanto no NT, frequentemente refere-se ao vasto espaço acima, no qual estão inclusos o sol, a lua, os planetas e as estrelas".22 Percebemos que, no início do relato da criação quando Deus cria os luminares do céu, ele fala que estes astros estavam no firmamento dos céus.

Uma das passagens bíblicas mais formidáveis que contém está expressão está no livro do profeta Isaías:

Porque, assim como os céus são mais altos do que a terra, assim são os meus caminhos mais altos que os vossos caminhos, [...]. Porque, assim como descem a chuva e a neve dos céus e para lá não tornam, sem que primeiro reguem a terra, [...], assim será a palavra que sair da minha boca: não voltará para mim vazia, mas fará o que me apraz e prosperará naquilo para que a designei (Isaias 55.9-11). ${ }^{23}$

Antes de descrevermos sobre o conceito de céu na Igreja Cristã Primitiva se faz necessário conhecer a religião que deu origem ao cristianismo primitivo, e analisar qual o conceito judaico de céu.

De acordo com Tenney:

acreditava-se que os justos viveriam, após a sua ressurreição, no jardim, ou no "paraíso" do Éden [...]. O conceito de paraíso entre os judeus précristãos era, assim, muito variável, e dava impressão de que o conceito cumpriu papéis diferentes. Muitos também acreditavam que o paraíso estava escondido em algum lugar; e ali viveriam os justos e os patriarcas eternamente. ${ }^{24}$

Apesar de acreditarem que havia uma quantidade de céus, os judeus eram bastante coerentes ao pensar sobre uma pluralidade céus, eles criam que havia sete céus onde Deus e os seres celestiais habitam, e de onde ele rege o universo.

Outra religião que se derivou do judaísmo, e tem a maior quantidade de adeptos ao redor do mundo e que carrega consigo a doutrina do céu como parte de suas crenças foi

22 TENNEY, 2008, p. 1021.

23 A BÍBLIA SAGRADA. São Paulo: SBB, 2000.

24 TENNEY, 2008, p. 757. 
o cristianismo. Os ensinamentos da Igreja Cristã em geral a respeito da recompensa dos justos não são diferentes do que a Bíblia ensina.

A palavra paraíso, por exemplo, também pode se referir ao céu. Alguns escritores da Igreja cristã primitiva usavam o termo paraíso diversas vezes em suas obras como se estivessem falando do céu. Agostinho fala do céu como "um lugar de felicidade onde a presença do bem é constante, e onde a vida consiste em um longo e constante louvor de exaltação a Deus" ${ }^{25}$

Os cristãos primitivos esperavam que o julgamento final estivesse próximo, e após este julgamento seria decidido o destino de todos; "indo os bons para o Paraíso e os maus para o Inferno". ${ }^{26}$ Vale ressaltar que o cristianismo apresenta certas semelhanças com algumas religiões, pois tem o céu como o lugar da supremacia divina. Segundo Félicien Challaye, "se Deus é o Iavé dos Profetas judeus tornando o Pai celeste. O céu onde vive é superior a terra, como o sagrado domina o profano em todos cultos primitivos, $[\ldots]]^{\prime 2}{ }^{27}$

A crença no céu foi se desenvolvendo paulatinamente na história da Igreja Católica fazendo parte do corpo de doutrinas do catolicismo. De igual maneira, no protestantismo, encontramos algumas obras nas quais se pode afirmar que o céu faz parte do corpo doutrinário das igrejas que a compõe; por exemplo, os estudos de Charles Hodge, apresentam o tema do céu partindo do pressuposto do reino que "seria estabelecido e foi predito por Deus no Antigo Testamento, o qual viria a ser universal e eterno" ${ }^{28}$

Enfim, tanto para o mundo católico quanto para o mundo protestante, por mais que já não se fale tanto na doutrina do céu, ainda assim o conceito de céu conforme descrito na Bíblia - ainda que na teoria - é predominantemente comum entras suas denominações religiosas.

\section{Da modernidade a contemporaneidade}

Não resta dúvida de que a Modernidade com o seu cunho racionalista influenciaram grandemente os teólogos católicos e consequentemente protestantes do início e meio do século XX. Pode-se dizer que o conceito de céu sofreu algumas transformações e passou a ser visto de uma perspectiva diferente a partir do Concílio Vaticano II.

O ser humano contemporâneo vive a sua fase de desencanto com a Modernidade, esta que assegurava que com o avanço da ciência o mundo mudaria para uma melhor

25 DEDEREN, 2011, p. 1061.

26 CHALLAYE, Félicien; SILVEIRA, Alcantara. Pequena história das grandes religiões. 2. ed. São Paulo: Instituição Brasileira de Difusão Cultural, 1967. p. 225.

27 CHALLAYE, 1967, p. 237.

28 HODGE, Charles. Teologia sistemática. São Paulo: Hagnos, 2001. p. 1648. 
qualidade de vida. O ser humano contemporâneo é um ser inconstante, não tem certeza do que quer na vida, muito menos do por que está aqui e qual o propósito da vida.

Como disse Verner Hoefelmann, “a maneira como se acredita na vida futura reflete na maneira como se vive a vida no presente" ${ }^{29}$ Não que devemos apreciar a primeira em detrimento da segunda, mas devemos entender que ambas estão correlacionadas entre si e precisam estar em comum acordo em nossa vida cotidiana.

A sociedade contemporânea está em constante mudança em todos os aspectos da vida. A busca pelo novo, em detrimento do que é considerado velho, tem sido sua incansável e constante maratona. No que diz respeito à vida religiosa não é diferente, a religião considerada tradicional com suas crenças e costumes já não faz sentido neste tempo.

O conjunto de crenças fundamentais da religião tradicional cristã não se enquadra no padrão de vida da sociedade pós-moderna. Estes valores que antes eram dogmáticos e que agora foi encarado como obsoletos, uma vez reformulados a condição de vida atual da humanidade também vai deixando de ser relevantes, pois não há espaço para algo sólido e concreto no pensamento do homem contemporâneo. Logo, o que importa é viver a vida e questionar a tudo aquilo que soa como arcaico desatualizado e cada um fazer seu próprio caminho em busca de sua própria paz interior.

O céu deixa de ser aquele lugar antes desejado por parte dos seres humanos e passa a ser uma esfera espiritualizada.

Como o céu não pode ser visibilizado ou tocado ou qualquer coisa do gênero é mais fácil não sonhar com este lugar. Fazer de conta que não existe tal lugar, e que este não passa de mito de fundamentalistas religiosos com seus interesses pessoais, se torna muito mais cômodo. É melhor conviver com o pensamento de que não temos que prestar contas a ninguém superior a nós - o Divino conforme a tradição cristã - que ficar presos à ideia de uma submissão religiosa a Deus.

Logo, o conceito de um Deus pessoal que interfere e atua na esfera humana não me é conveniente; sendo assim, é preferível espiritualizar a dogmatizar a fé. Deus, inferno e céu, são melhor não existir.

\section{Considerações finais}

No decorrer deste trabalho, notamos que não apenas em escritos registrados na história, mas igualmente na arquitetura de algumas culturas e religiões antigas o conceito de céu sempre esteve presente em seu cotidiano.

29 SOUZA, Tiago Dias de. Do outro lado da vida: A apologia paulina da ressurreição em 1 Coríntios 15 . São Leopoldo: Oikos, 2016. p. 9. 
Os babilônicos, por exemplo, tinham a crença de que no céu estava o deus soberano, aquele que governava todos os outros deuses. Os egípcios por sua vez, acreditavam que o céu seria o lugar onde desfrutaria de todos os prazeres desta vida em sua totalidade. Talvez os gregos fossem quem desenvolveram o conceito de céu parecido com o que se acredita no mundo atual. Os filósofos falavam do céu como o "cosmo" dividido em suas divisões astronômicas como também espiritual.

Em religiões de origem oriental, tais como budismo, hinduísmo e islamismo a grandiosidade do céu sempre esteve presente na vida de seus adeptos. Por mais que o Budismo não fale do Deus dos cristãos, eles acreditam na doutrina do paraíso ocidental, como também na existência de céus individuais dos budas. Por outro lado, os hindus creem em uma série de céus chamados "locas" onde se conclui o ciclo da vida e o ponto mais alto da união com Brahama. Já os mulçumanos acreditam que existem sete céus.

Em religiões de origem bíblicas como é o caso do judaísmo, cristianismo, catolicismo e protestantismo, o céu foi usado tanto no Antigo e Novo Testamento com diversos significados. Ele pode se referir a grandes divisões do universo e de igual modo ao lugar onde mora Deus e os seres celestiais.

No entanto, pouco se tem pregado ou escrito sobre o céu. Foi somente na Idade Média que os escolásticos se puseram a estudar o céu com mais detalhes. Ainda assim, encontram-se declarações do céu no catolicismo romano; como, por exemplo, no credo, em hinos e poemas do período medieval, e em alguns livros e escrito por autores católicos.

A despeito de todas estas informações supracitadas fica evidente que a noção de céu não é apenas algo que pertence à religião cristã, ele está relacionado a povos e culturas desde as mais remotas até as atuais. No entanto, no decorrer dos tempos e em específico neste século presente, o que notamos é uma forte ênfase em espiritualizar o céu, deixando este de ser um lugar.

\section{Referências}

A BÍBLIA SAGRADA. São Paulo: SBB, 2000.

ABBAGNANO, Nicola. Dicionário de filosofia. 5. ed. São Paulo: Martins Fontes, 2007.

BROWN, Colin; COENEN, Lothar (Org.). Dicionário internacional de teologia do Novo Testamento. 2. ed. São Paulo: Vida Nova, 2000.

CHALLAYE, Félicien; SILVEIRA, Alcantara. Pequena história das grandes religiões. 2. ed. São Paulo: Instituição Brasileira de Difusão Cultural, 1967.

DEDEREN, R. (Ed.). Tratado de teologia Adventista do Sétimo Dia. Tatuí: CPB, 2011.

ELIADE, Mircea. Tratado de História das Religiões. São Paulo: Martins Fontes, 1998. 
HODGE, Charles. Teologia sistemática. São Paulo: Hagnos, 2001.

KONIG, F.; WALDENFELS, H.; SANDER, L. M. Léxico das religiões. Petrópolis: Vozes, 1998.

LEITE FILHO, Tácito da Gama. As religiões antigas. Rio de Janeiro: JUERP, 1994.

LIBÂNIO, João B; BINGEMER, Maria Clara L. A libertação na história: escatologia cristã. Petrópolis: Vozes, 1985.

SCHLESINGER, Hugo; PORTO, Humberto. Dicionário enciclopédico das religiões. Petrópolis: Vozes/Campus, 1995.

SOUZA, Tiago Dias de. Do outro lado da vida: A apologia paulina da ressurreição em 1 Coríntios 15. São Leopoldo: Oikos, 2016.

TENNEY, Merrill C. (Org.). Enciclopédia da Bíblia. São Paulo: Cultura Cristã, 2008.

TREIYER, Humberto R. Religiones comparadas. Entre Rios: S.E.M. Colégio Adventista Del Plata, 1966. 